Гераскина Анастасия Александровна, магистр, Саратовский государственный аграрный университет имени Н.И. Вавилова. Россия.

410012, г. Саратов, Театральная пл., 1.

Тел.: (8452) 26-16-88.
Ключевые слова: гибриды кукурузы; микробиологическое удобрение; урожайность зерна; густота стояния растений.

\title{
THE EFFECT OF MICROBIOLOGICAL FERTILIZER AND PLANT STAND ON THE YIELD OF CORN HY- BRIDS GRAIN IN THE LOWER VOLGA REGION
}

Gudova Lyudmila Aleksandrovna, Candidate of Agricultural Sciences, Leading Researcher, Russian Research Institute for Sorghum and Maize "Rossorgo". Russia.

Zhuzhukin Valeriy Ivanovich, Doctor of Agricultural Sciences, Professor, of the chair "Crop production, Selection and Genetics", Saratov State Agrarian University named after N.I. Vavilov. Russia.

Zaytsev Sergey Aleksandrovich, Candidate of Agricultural Sciences, Leading Researcher, Russian Research Institute for Sorghum and Maize "Rossorgo". Russia.

Volkov Dmitriy Petrovich, Senior Researcher, Russian Research Institute for Sorghum and Maize "Rossorgo". Russia.

Geraskina Anastasiya Aleksandrovna, Magister, Saratov State Agrarian University named after N.I. Vavilov. Russia.

Keywords: maize hybrids; microbiological fertilizer; grain yield; plant stand.

The results of studies of the three-factor experiment, which allows determining the effects of the microbiological fertilizer Extrasol (factor C) and plant stand (factor B) on the yield of corn hybrids (factor A), are presented. It was established that in 2014, an early ripening hybrid Ross 197 MW had a higher average yield - 5.46 t/ha. In 2015 and 2016, middle-early ripening hybrid Ross $299 \mathrm{MW}$ was more productive -6.85 and $5.97 \mathrm{t} / \mathrm{ha}$ respectively. During the experiment, middle-late hybrid STK 175MV did not realize the potential yield due to lack of moisture during the growing season. Hybrids have a tendency to increase grain yield with an increase in the number of plants per unit area. The grain yield by factor $B$ in 2014 was 3.23-7.25 t/ha; in 2015-3,80-8,41 t/ha; in 2016-3.91-6.19t/ha. The variability of the sign "grain yield" in 2014 and 2015 was influenced by factor B (plant stand) - 79.0 and $82.30 \%$, respectively. In 2016, the influence of factor $B$ was slightly lower $-47.0 \%$, but at the same time the influence of factor A (hybrid) increased - $33.6 \%$.

удк 633.15:631.527

\section{ОЦЕНКА ЭФФЕКТИВНОСТИ ГАПЛОИНДУКТОРА кУкУрУзЫ ЗМс-п}

\author{
ГУТОРОВА Ольга Валентиновна, Саратовский национальный исследовательский \\ государственный университет имени Н.Г. Чернышевского
}

ЮдАКОВА Ольга Ивановна, Саратовский нацииональый исследовательский государственный университет имени Н.Г. Чернышевского

ЗАЙЦЕВ Сергей Александрович, Российский научно-исследовательский и проектнотехнологический институт сорго и кукурузы

Приведены результаты оценки способности киндукиии образования гаплоидов семей (потомство одного початка) создаваемой гаплоиндуцирующей линии кукурузы ЗМС-П. В качестве материнских форм использовали растения 53 гибридов и одной сортопопулящии, в качестве отцовских форм - растения 21 семъи линии ЗМС-П. С помощъю метода генетического маркирования был проведен отбор зерновок с гаплоидным зародышем среди гибридных семян. Частота образования гаплоидов в полученном гибридном потомстве при скрещивании с разными материнскими формами варьировала от 0 до 15,8\%. Средняя частота гаплоиндукиии по семъям варъировала от 1,3 до 7,0 \%. Средняя частота гаплоиндукиии составила 4,8 1,7 \%. Таким образом, линия ЗМС-П является эффективным гаплоиндуктором, который можно использовать для массового получения гаплоидов и ускоренного создания на их основе новых гомозиготных линий кукурузы.

Введение. Ценным исходным материалом для создания высокогетерозисных гибридов кукурузы являются гомозиготные линии. Для создания их традиционным методом самоопыления требуется не менее 6 лет работы. Использование в селекции гаплоидии in vivo и in vitro ускоряет процесс выведения таких линий до двух лет. В основе данных технологий лежит индукция развития гаплоидов, которые далее подвергают диплоидизации. В случае ее успешного прохождения, фертильные диплоидизированные растения самоопыляют и получают первое поколение новой гомозиготной линии [4, 6-8]. Одним 
из эффективных и быстрых методов получения гаплоидов у кукурузы является использование линий-гаплоиндукторов $[3,5$, $9,10]$. При опылении пыльцой гаплоиндукторов материнских растений других линий среди гибридного потомства формируются зерновки с гаплоидными зародышами материнского типа.

В Саратовском госуниверситете продолжаются селекционно-генетические работы по выведению на основе ранее созданной линии 3МС-8 новых высокоэффективных линий-гаплоиндукторов под рабочим названием 3МС-П $[1,2]$. В отличие от 3МС-8, линии 3МС-П наряду с доминантными генами-маркерами пурпурной окраски зародыша и эндосперма характеризуются также пурпурной окраской частей взрослых растений. Для создания новых линий используют семейный и индивидуальный отбор. Семейный отбор заключается в тестировании потомства одного початка на эффективность и универсальность гаплоиндукции. Под эффективностью гаплоиндукции понимают частоту образования гаплоидов в гибридном потомстве, под универсальностью - способность индуцировать развитие гаплоидов у разных материнских форм. Индивидуальный отбор проводится внутри семьи и включает в себя отбор для дальнейшего воспроизводства растений с наилучшими показателями таких характеристик, как высота растения, продуктивность метелки, неполегаемость и др.

Цель исследований - оценка эффективности и универсальности разных семей гаплоиндуцирующей линии кукурузы 3МС-П.

Методика исследований. Материалом исследования послужили растения 21 семьи (потомства одного початка) гаплоиндуктора ЗМС-П. Зрелую пыльцу этих растений собирали и наносили на рыльца изолированных початков. В качестве материнских форм использовали растения 53 гибридов и 1 сортопопуляции российской селекции (см. таблицу).

Полученные гибридные зерновки подразделяли на имеющие маркированные окрашенные эндосперм и зародыш (гибридные эндосперм и зародыш) и зерновки с маркированным эндоспермом и немаркированным зародышем (предполагаемые гаплоиды, гибридный только эндосперм).

Частоту образования гаплоидов (частоту гаплоиндукции) определяли как процентное отношение количества зерновок с предполагаемыми гаплоидными зародышами к обще- му количеству гибридных зерновок. Всего проанализировали около 600 початков.

Результаты исследований. Результаты исследования показали, что частота индукции развития гаплоидов при опылении пыльцой растений 3МС-П варьировала от 0 до 15,8 \%. У раннеспелых материнских форм завязывались единичные зерновки, среди которых практически не встречались семена с гаплоидными зародышами. Из-за отсутствия зрелой пыльцы ЗМС-П в период массового цветения раннеспелых материнских форм происходила вынужденная задержка опыления. Иногда такая задержка сама может индуцировать развитие зародышей без оплодотворения. Например, данное явление описано у линий кукурузы, склонных к наследуемому партеногенезу [1]. Однако крайне низкая завязываемость семян и отсутствие гаплоидов в потомстве от скрещивания ЗМС-П с раннеспелыми материнскими формами, с одной стороны, свидетельствует о том, что у изученных материнских форм отсутствует наследуемая предрасположенность к партеногенезу, и, с другой - длительная задержка опыления снижает восприимчивость рылец к опылению.

В скрещиваниях, где завязывалось достаточное количество семян, частота гаплодии зависела от генотипа как материнской, так и отцовской формы. Например, пыльца растений семьи 93-94 (см. таблицу) индуцировала партеногенетическое развитие зародышей у гибрида Услада с частотой 15,8 \%, а у растений КС 216 лишь с частотой 2,5\%. В то же время количество гаплоидов у КС 216 при использовании растений семьи 95-96 в потомстве составило 5,8 \%. Исходя из полученных данных, можно выделить как перспективные для дальнейших селекционных работ семьи ЗСМ-П, так и наиболее восприимчивые к гаплоиндукции гибриды. Наиболее эффективными в проведенных скрещиваниях оказались семьи гаплоиндуктора 88-89, 107-108 и 111-112.

Заключение. Способность к индукции матроклинных гаплоидов у семей линии 3СМ-П проявилась практически на всех протестированных материнских формах. Средняя частота гаплоиндукции линии ЗСМ-П по всем семьям составила $4,8 \pm 1,7 \%$, что характеризует ее как универсального и эффективного гаплоиндуктора. Таким образом, гаплоиндуктор ЗСМ-П можно использовать для массового получения гаплоидов, 


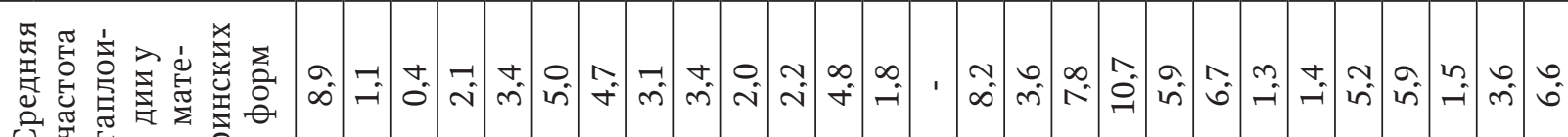

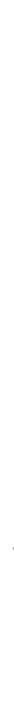

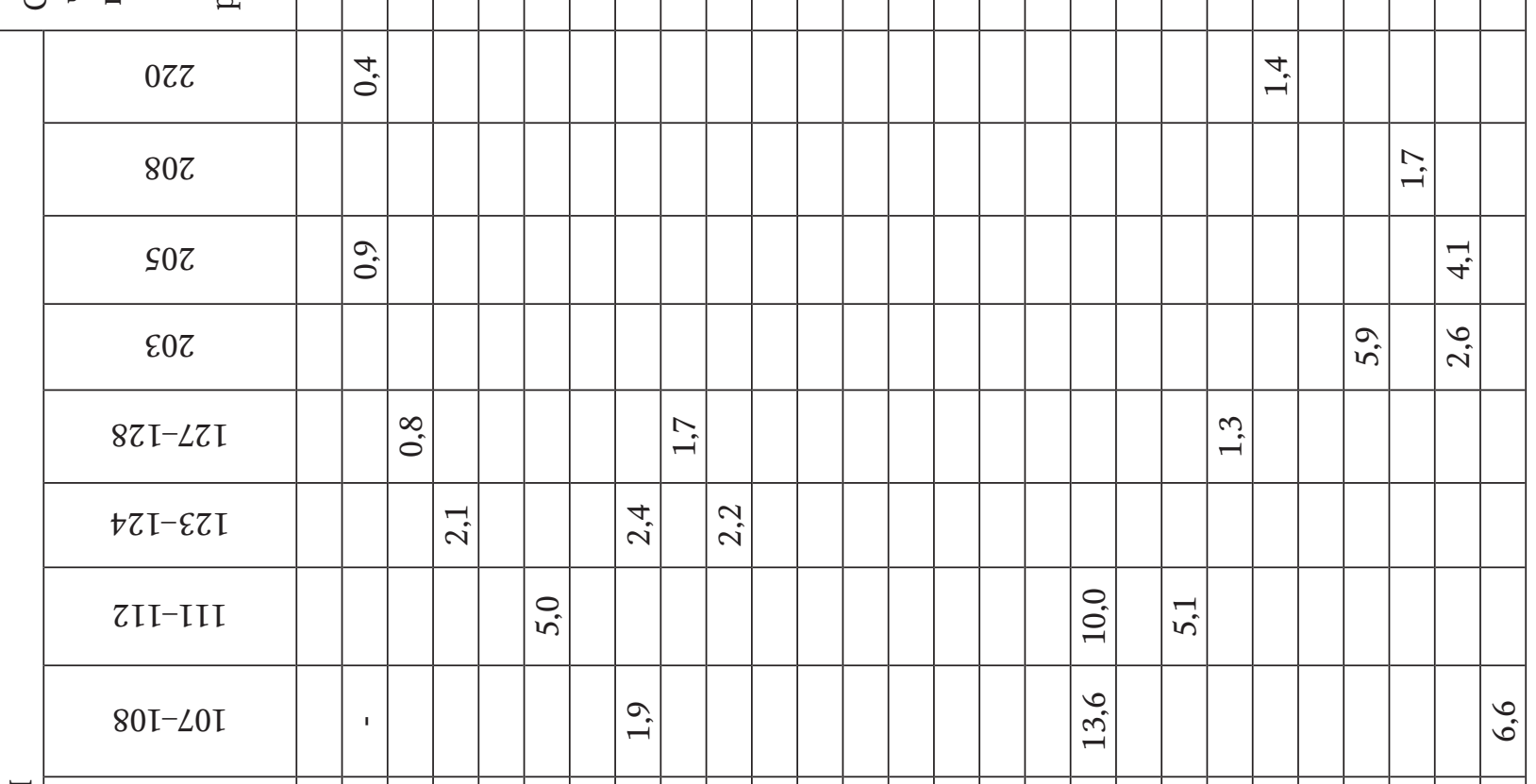

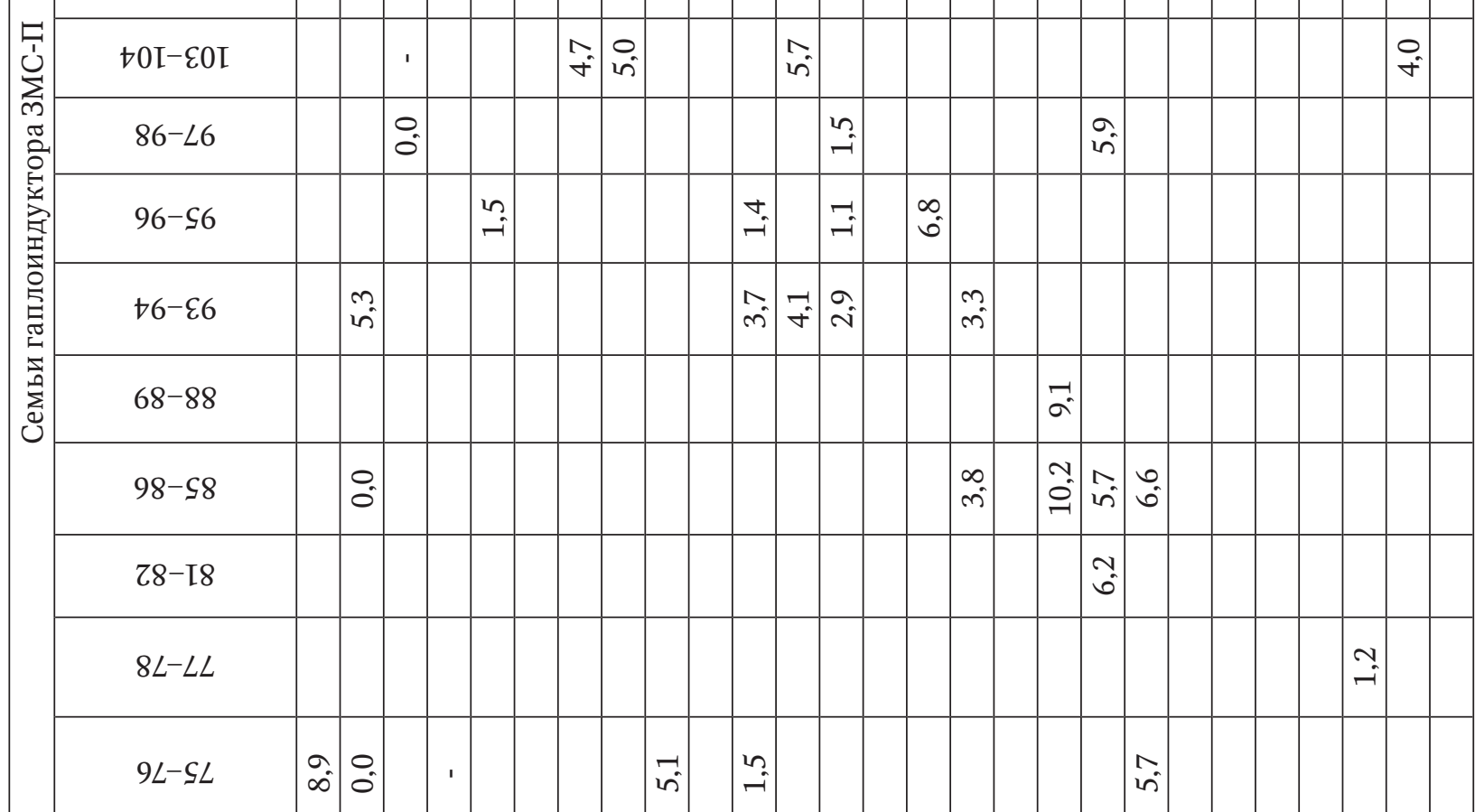

$\downarrow L-\varepsilon L$

is

$\stackrel{\infty}{\rightarrow-}$

$Z L-I L$

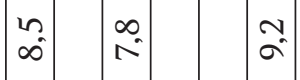

89- 29

a.

ติ

99-\$9

잉

n.

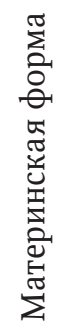

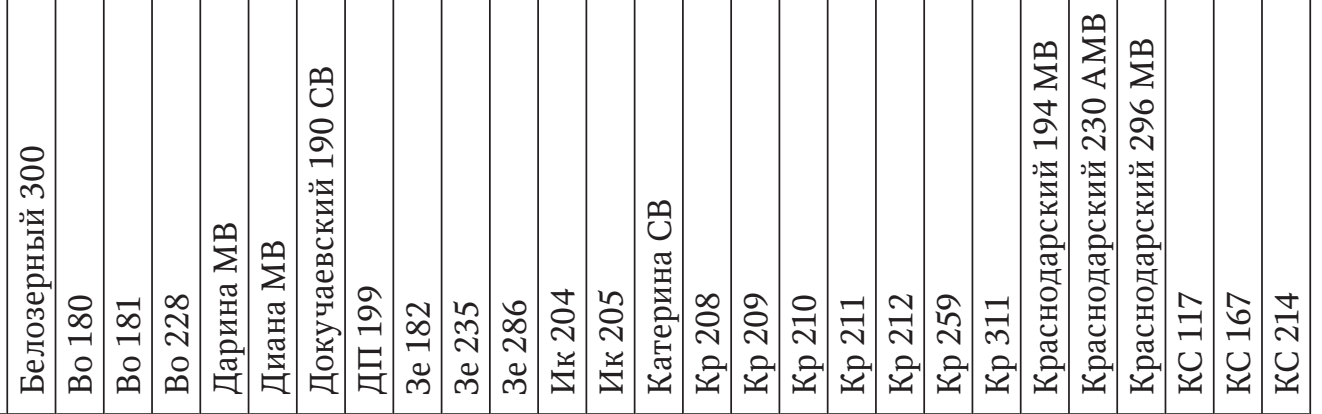




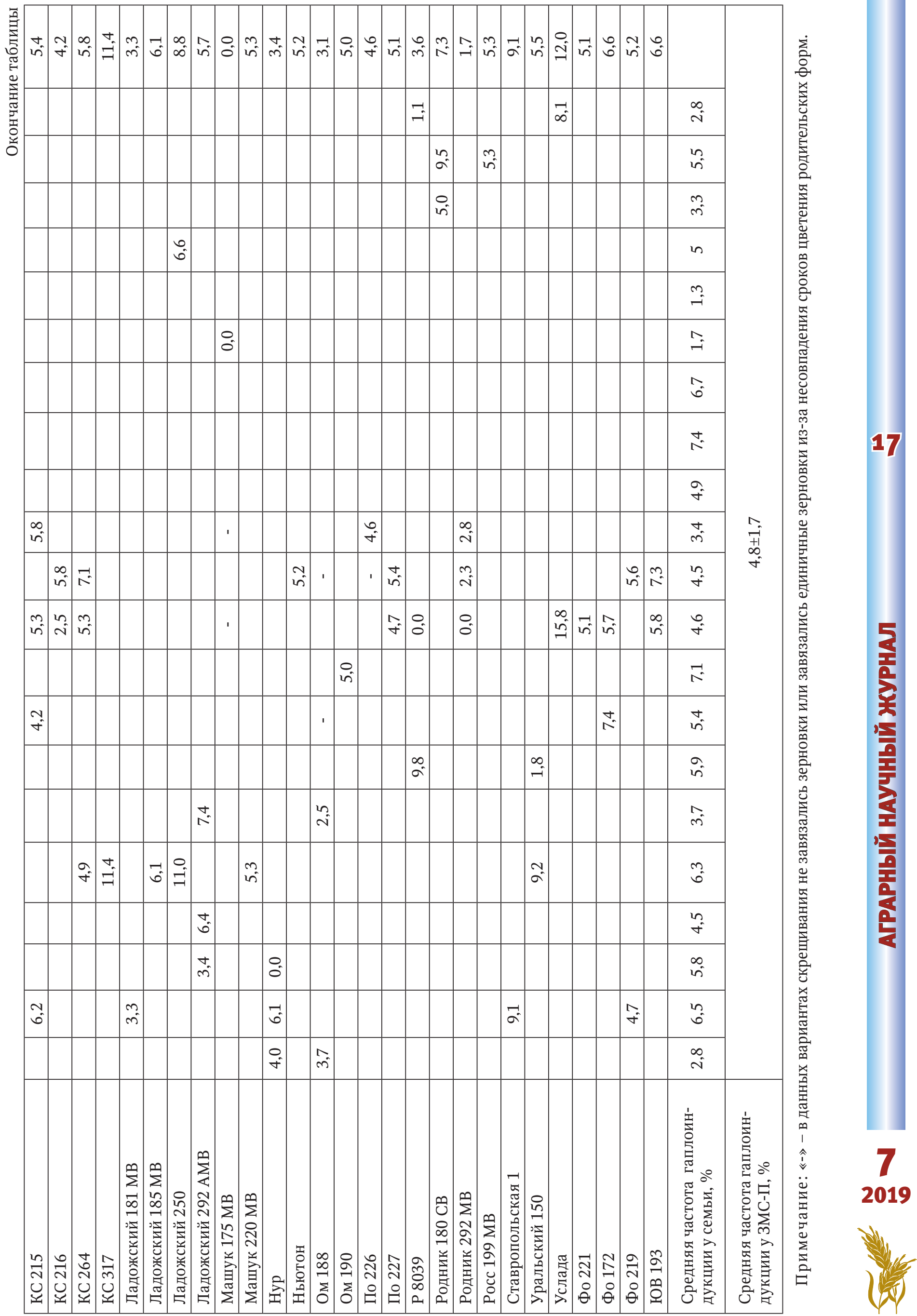


преимущественно у среднеспелых и позднеспелых форм кукурузы, для ускоренного создания на их основе новых гомозиготных линий кукурузы. Вместе с тем актуальность выведения раннеспелых форм кукурузы для выращивания их в средних широтах ставит необходимость продолжения селекционных работ по созданию раннецветущих гаплоиндуцирующих линий.

Работа выполнена при частичной финансовой поддержке Минобрнауки России в рамках базовой части государственного задания в сфере научной деятельности по заданию № 6.8789.2017/БЧ.

\section{СПИСОК ЛИТЕРАТУРЫ}

1. Апанасова Н. В., Гуторова О. В., Юдакова О. И., Смолькина Ю. В. Особенности строения и развития женских генеративных структур у линий кукурузы с наследуемым и индуцированным типами партеногенеза // Известия Самарского научного центра Российской академии наук. - 2017. - Т. 19. - № 2-2. C. 216-219.

2. Гуторова О.В., Апанасова Н.В., Юдакова О.И. Создание генетически маркированных линий кукурузы с наследуемым и индуцированным типами партеногенеза // Известия Самарского научного центра Российской академии наук. - 2016. T. 18. - № 2-2. - C. 341-344.

3. Шацккая О.А. Создание гаплоиндукторов кукурузы: три цикла отбора на высокую частоту индукции матроклинных гаплоидов // Сельскохозяйственная биология. - 2010. - № 5. - С. 79-86.

4. Battistelli G.M. et al. Production and identification of doubled haploids in tropical maize // Genetics and Molecular Research, 2013, Vol. 12, № 4, P. 4230-4242.

5. Hu H. et al. The genetic basis of haploid induction in maize identified with a novel genome-wide association method // Genetics, 2016, Vol. 202, P. 1267-1276.

6. Geiger H.H. Doubled haploids // Maize Handbook, Vol. II: Genetics and Genomics, Heidelberg, New York: Springer Verlag, 2009, P. 641-659.

7. Geiger H., Gordillo G. Doubled haploids in hybrid maize breeding // Maydica, 2009, Vol. 54, P. 485-499.

8. Kalinowska K. et al. State-of-the-art and novel developments of in vivo haploid technologies / Theoretical and Applied Genetics, 2018, № 5, P. 1-13.

9. Rotarenco V., Dicu G., Sarmaniuc M. Induction of maternal haploids in maize // Maize Genetic Cooperation Newsletter, 2009, P. 15-17.

10. Sarmaniuc $M$. The recombination of different inducers, as source of new haploid induction lines creation in maize // Культурные растения для устойчивого сельского хозяйства в XXI веке (иммунитет, селекция, интродукция). - T. IV. - Ч. II / Россельхозакадемия. - М., 2011. - С. 161-164.

Гуторова Ольга Валентиновна, ассистент кафедры генетики, Саратовский национальный исследовательский государственный университет имени Н.Г. Чернышевского. Россия.

Юдакова Ольга Ивановна, $\partial-p$ биол. наук, $\partial e$ кан биологического факультета, Саратовский национальный исследовательский государственный университет имени Н.Г. Чернышевского. Россия.

410012, г. Саратов, ул. Астраханская, 83, корпус 5.

Тел.: (8452)51-16-3.

Зайцев Сергей Александрович, канд. с.-х. наук, старший научный сотрудник, Российский научно-исследовательский и проектно-технологический институт сорго и кукурузы. Россия.

410050, г. Саратов, 1-й Институтский проезд, 4. Тел.: (8452) 79-49-69.

Ключевые слова: Zеa тауs; кукуруза; гаплоид; метод генетического маркирования; гаплоидия; гаплоиндукция; селекция.

\section{THE EFFECTIVENESS EVALUATION OF THE HAPLOID INDUCER OF MAIZE LINE ZMS-P}

Gutorova Olga Valentinovna, Assistant of the chair "Genetics”, Saratov State Research State University named after N.G. Chernyshevskiy. Russia.

Yudakova Olga Ivanovna, Doctor of Biological Sciences, Saratov State Research State University named after N.G. Chernyshevskiy. Russia.

Zaytsev Sergey Aleksandrovich, Candidate of Agricultural Sciences, Senior Researcher, Russian Scientific Research and Project-technological Institute of Sorghum and Corn "Rossorgo". Russia.

Keywords: Zea mays; corn; haploid; genetic marking method; haploidy; haploid induction; selection.

The results of the assessment of the ability to induce of haploid formation in the families (offspring of one ear) of the created haploid inducing maize line ZMS-P are given. 53 hybrids and one cultivar population were used as maternal forms, and 21 families of the ZMS-P line were used as paternal forms. The kernels with haploid embryos were selected among hybrid seeds with using the method of genetic marking. The frequency of haploids in the offspring ranged from 0 to $15.8 \%$. The average frequency of haploid induction in families of the ZMS-P line varied from 1,3 to 7,0\%. The average frequency of haploid induction is 4,8 $\pm 1,7 \%$. Thus, the ZMS-P line is an effective haploid inducer that can be used for mass production of haploids and the rapid creation of new homozygous maize lines. 